Propuesta de un plan de desarrollo turístico para la región geográfica del cantón Quero

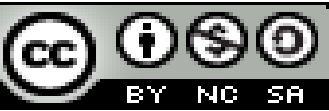

Ciencias económicas y empresariales

Artículo de investigación

\title{
Propuesta de un plan de desarrollo turístico para la región geográfica del cantón Quero
}

\section{Proposal for a tourism development plan for the geographical region of the Quero canton}

\section{Proposta de um plano de desenvolvimento turístico para a região geográfica do cantão de Quero}

\author{
Catalina M. Verdugo-Bernal ${ }^{\mathrm{I}}$ \\ cverdugo@hotmail.com \\ Julia D. Velastegui-Caceres II \\ julia.velastegui@espoch.edu.ec \\ Cecilia T. Limaico-Nieto ${ }^{\text {III }}$ \\ cecilia.limaico@espoch.edu.ec \\ Diana P. Salazar-Andrade IV \\ diana.salazar@utc.edu.ec \\ Ana C. Flores-Mancheno ${ }^{\mathrm{IV}}$ \\ ana.flores@espoch.edu.ec
}

Recibido: 22 de septiembre de $2018 *$ Corregido: 26 de octubre de $2018 *$ Aceptado: 21 de diciembre de 2018

I. Magíster en Turismo Sostenible y Desarrollo Local, Especialista Superior en Gestión Ambiental Mención Amazonia y Derechos Humanos, Máster en Diseño, Gestión y Dirección de Proyectos, Ingeniera en Ecoturismo, Docente Investigadora de la Escuela Politécnica de Chimborazo ESPOCH, Riobamba, Ecuador.

II. Máster of Sciene in Geospatial Technologies, Ingeniera Geógrafa y del Medio Ambiente, Docente Investigadora de la Escuela Politécnica de Chimborazo ESPOCH, Riobamba, Ecuador.

III. Magíster en Educación Matemática, Doctora en Física, Licenciada en Ciencias de la Educación Profesora de Enseñanza Media en la Especialización de Matemática y Física, Docente Investigadora de la Escuela Politécnica de Chimborazo ESPOCH, Riobamba, Ecuador.

Iv. Magíster en Turismo Sostenible y Desarrollo Local, Ingeniera En Ecoturismo, Ingeniera en Ecoturismo Docente Investigadora Universidad Técnica de Cotopaxi, Latacunga, Ecuador.

v. Máster Universitario en Estadística Aplicada, Ingeniera en Estadística Informática, Docente Investigadora de la Escuela Politécnica de Chimborazo ESPOCH, Riobamba, Ecuador. 


\title{
Resumen
}

El cantón Quero, es una población rodeada de flora y fauna abundante que hacen agradable su visita, además de su gente amable que está muy interesada en convertir a su localidad en un destino turístico potencial mediante la incorporación de proyectos articulados de ecoturismo a escala local y regional. Para fortalecer el turismo en la región, se propone, en este artículo, elaborar un plan turístico de trabajo para dicho cantón. La metodología fue de tipo descriptivo y se realizó en cuatro pasos, en primer lugar, se evaluó el potencial e inventario turístico de la zona. Posterior se elaboró el marco filosófico y estratégico del plan; en un tercer momento se presenta el programa y proyecto de desarrollo turístico y por último la estructura y proyecto de plan operativo anual (POA). Entre los resultados se pudo constatar que la demanda se inclina por el turismo de naturaleza, donde la oferta turística existente no satisface el tamaño de la demanda y en sus cantones aledaños ya se encuentran ejecutando planes para desarrollar el turismo en su zona. Se concluye que la ejecución del presente plan ubica las bases para mejorar el turismo del cantón.

Palabras clave: desarrollo turístico; potencial turístico; inventario de atractivos turísticos.

\begin{abstract}
The Quero canton is a town surrounded by abundant flora and fauna that make your visit enjoyable, as well as its friendly people who are very interested in converting their locality into a potential tourist destination by incorporating articulated ecotourism projects on a local scale and regional. In order to strengthen tourism in the region, it is proposed, in this article, to elaborate a tourist work plan for said canton. The methodology was descriptive and was carried out in four steps, firstly, the potential and tourist inventory of the area was evaluated. Later the philosophical and strategic framework of the plan was elaborated; in a third moment the program and project of tourist development is presented and finally the structure and project of annual operative plan (AOP). Among the results it was found that the demand is for tourism of nature, where the existing tourism supply does not meet the size of the demand and in its neighboring cantons are already executing plans to develop tourism in their area. It is concluded that the execution of the present plan locates the bases to improve the tourism of the canton.
\end{abstract}

Keywords: tourism development; tourist potential; inventory of tourist attractions.

\section{Resumo}


O cantão Quero, é uma cidade rodeada por abundante flora e fauna que fazem agradável sua visita, além de seu povo hospitaleiro que estão muito interessados em transformar sua cidade em um potencial destino turístico através da incorporação de projetos articulados ecoturismo local e regional Para fortalecer o turismo na região, propõe-se, neste artigo, elaborar um plano de trabalho turístico para o referido cantão. A metodologia foi descritiva e foi realizada em quatro etapas, primeiramente, foi avaliado o potencial e inventário turístico da área. Mais tarde, o quadro filosófico e estratégico do plano foi elaborado; em um terceiro momento é apresentado o programa e projeto de desenvolvimento turístico e, finalmente, a estrutura e projeto do plano operativo anual (POA). Entre os resultados verificou-se que a demanda prefere turismo de natureza, onde a oferta turística existente não atende o tamanho da demanda e seus cantões vizinhos já estão implementando planos para desenvolver o turismo em sua área. Conclui-se que a execução do presente plano localiza as bases para melhorar o turismo do cantão.

Palavras chave: desenvolvimento do turismo; potencial turístico; inventário de atrações turísticas.

\section{Introducción}

La mega diversidad del planeta tiene su morada en Ecuador, el centro del mundo, escenario de una sorprendente naturaleza, de culturas diversas y de las más variadas costumbres. Ubicado al noreste de Sudamérica, Ecuador cuenta con tesoros naturales como las Islas Galápagos, la exótica selva amazónica y majestuosos volcanes como el Chimborazo y el Cotopaxi.

En tal sentido, cabe destacar que el turismo presenta un claro crecimiento a nivel mundial del $4.3 \%$, llegando a convertirse en un motor de desarrollo económico que crece con mayor rapidez en el mundo como en América Latina, esto impulsado por algunos factores como la globalización, la cultura del ocio, el cuidado de la salud, la tendencia a la protección ambiental, el auge de la economía mundial, entre otros (World travel, 2014).

Según la Dirección de Investigación del Ministerio de Turismo, en octubre de 2013 Ecuador alcanzó un millón de ingresos de turistas en su mayoría provenientes de Colombia, Estados Unidos y Perú. Entre el 1 de enero y el 24 de agosto de 2014 arribaron al país 1.009.665 turistas, una cifra que representó un alto crecimiento con respecto a otros años; siendo el objetivo principal lograr el arribo de 1.5 millones de turistas extranjeros hasta diciembre de 2014 (Ministerio de Turismo de Ecuador. 2014). Es de indicar que el Cantón Quero, posee los recursos necesarios y el interés de 
la población quereña para promover el turismo, sin embargo, a pesar de contar con un Plan de Ordenamiento Territorial, y un marco legal que les ampara, no posee una herramienta que articule la gestión sostenible de su patrimonio turístico, presumiblemente como producto de la ausencia de una planificación previa que oriente la inversión pública, facilite la asistencia técnica y además involucre a todos los actores del sector turístico.

En la actualidad, Quero es un cantón agrícola que se ha visto afectado debido a la caída de ceniza frecuente por lo que los habitantes buscan nuevas alternativas para fomentar el progreso de su cantón y han definido como acción prioritaria el desarrollo del turismo para lograr su propósito, sin embargo, no cuenta con una estrategia elaborada técnicamente que les permita desarrollar la actividad turística.

Cabe señalar que, de acuerdo con la Constitución del Ecuador en el capítulo segundo, sección primera el Art. 13 enuncia que: las personas y colectividades tienen derecho al acceso seguro y permanente a alimentos sanos, suficientes y nutritivos; preferentemente producidos a nivel local y en correspondencia con sus diversas identidades y tradiciones culturales. Relacionándose estrechamente con el Artículo 14, 15 afirmando que: "Se reconoce el derecho de la población a vivir en un ambiente sano y ecológicamente equilibrado, que garantice la sostenibilidad y el buen vivir, Sumak kawsay. Se declara de interés público la preservación del ambiente la conservación de los ecosistemas, la biodiversidad y la integridad del patrimonio genético del país, la preservación del daño ambiental y la recuperación de los espacios naturales degradados.

Ante lo expuesto, se presenta un plan de desarrollo turístico para el cantón Quero, el cual contribuiría a identificar programas y proyectos de intervención en diferentes áreas para aprovechar de mejor manera los recursos del patrimonio natural y cultural que posee la zona, y a su vez sea un orientador de la inversión pública en materia turística y logrando así con el objetivo del Plan Nacional del buen vivir (Sumak Kawsay) que es el mejoramiento de la calidad de vida de los pobladores, en este caso de la población quereña.

\section{Desarrollo}

La Secretaria de Turismo de México (Sectur, 2012), menciona que el turismo es un fenómeno social que consiste en el desplazamiento voluntario y temporal de individuos o grupos de personas que, fundamentalmente por motivos de recreación, descanso o salud, se trasladan de su lugar de 
residencia habitual a otro, en el que no se ejerce ninguna actividad lucrativa ni remunerativa, generando múltiples interrelaciones de importancia social, económica y cultural.

Según la Organización Mundial de Turismo (2007), el turismo comprende las actividades que lo hacen las personas durante sus viajes y estancias en lugares distintos al de su entorno habitual, por un período consecutivo inferior a un año, con fines de ocio, por negocios o por otros motivos, además menciona que el turismo es la suma de relaciones y de servicios resultantes de un cambio de residencia temporal o voluntaria.

Turismo sostenible. Aquellas actividades turísticas respetuosas con el medio natural, cultural y social, y con los valores de una comunidad, que permite disfrutar de un positivo intercambio de experiencias entre residentes y visitantes, donde la relación entre el turista y la comunidad es justa y los beneficios de la actividad es repartida de forma equitativa, y donde los visitantes tienen una actitud verdaderamente participativa en su experiencia de viaje (Organización Mundial de Turismo, 2007).

Turismo consciente. El turismo consciente es una experiencia de vida transformadora que genera un crecimiento personal que nos convierte en mejores seres humanos. Este nuevo concepto se sustenta en los principios de sostenibilidad y ética y promueve los valores de la paz, la amistad, el respeto y el amor a la vida como la esencia de la práctica turística. Constituye un pacto de convivencia, responsabilidad, respeto mutuo y comunión entre los agentes turísticos de las comunidades emisoras y receptoras, el turista y el patrimonio natural y cultural. El turismo consciente es un concepto vivo, dinámico y en constante construcción. Es una experiencia del dar y recibir (Ministerio de turismo del Ecuador, 2012).

Plan de desarrollo turístico. Un plan de desarrollo es una herramienta de gestión que promueve el desarrollo social en un determinado territorio. De esta manera, sienta las bases para atender las necesidades insatisfechas de la población y para mejorar la calidad de vida de todos los ciudadanos. Dicha planificación debe contar con el consenso de los agentes públicos y privados, de los actores socioculturales y de los miembros de las comunidades que integran el producto cultural, recreativo y turístico, con el fin de atenuar las incertidumbres y generar compromisos de participación. (Horwath, 2006) 
El plan indica Águila (2008), "Es el término de carácter más global, referencia a decisiones generales que expresan los lineamientos políticos fundamentales, las prioridades que se derivan de esas formulaciones, la asignación de recursos acorde a esas prioridades, las estrategias de acción y el conjunto de medios e instrumentos que se van a utilizar para alcanzar las metas y objetivos" (p.55).

\section{Planificación del desarrollo}

La planificación del desarrollo, explica Saavedra (2001), se concibe como un proceso dirigido a orientar el cambio social, en el cual los diferentes actores sociales intervienen de manera sistemática en el presente para construir el futuro garantizando el logro del desarrollo deseado y posible, protegiendo las opciones para las generaciones futuras.

El mismo autor, indica que en esta concepción se destaca los siguientes elementos:

- Planificar un proceso cuya validación es ante todo social y por lo tanto, se debe dar como resultado de la participación no solamente del estado, sino también de los diferentes actores que conforman la sociedad.

- La participación generadora del consenso, reconociendo la propia responsabilidad que tienen los diferentes actores sociales de definir el futuro que les tocara vivir, y a su vez, el desafío planteado a cada uno de no limitarse hacer solo espectador sino constructor de eseporvenir.

- Pensar en el futuro para actuar en forma transcendente en el presente, facilitando y apoyando la gestión, pero también generando cabio y resultados.

- La visión holística, articulando e integrando los diversos procesos, subprocesos y componentes que se requieren para el desarrollo.

\section{Evaluación del potencial turístico}

El turismo destaca como aquella actividad capaz de generar efectos multiplicadores de empleo y producción, tanto directa como indirectamente y de manera descentralizada. Las tendencias mundiales respecto al concepto de turismo y la variedad de atractivos disponibles en diferentes partes del país, sustentan la potencialidad que tiene el turismo. 
Según la Organización Mundial de Turismo (OMT) la evaluación del potencial turístico de una zona permitirá determinar el territorio correspondiente en el que se llevará a cabo el proyecto de desarrollo turístico una evaluación precisa del potencial turístico del territorio constituye una excelente base de adopción de decisiones para los organismos de desarrollo, ya que les permitirá minimizar los riesgos de implicarse en malas inversiones (Tierra, P. 2008).

\section{Metodología}

La metodología fue de tipo descriptica y de campo. La recolección de la información para validar la evaluación del potencial turístico y al análisis del diagnóstico situacional del cantón se realizó mediante salidas de campo, reuniones, talleres con los representantes del ámbito turístico y juntas parroquiales y líderes comunitarios y algunas fuentes secundarias como el plan de desarrollo cantonal, investigaciones e informes técnicos realizados en el mismo. Para el análisis de la oferta se realizó el inventario de los atractivos naturales y culturales existentes en el Cantón Quero a través de la metodología del MINTUR 2004, adaptada por (Cajas y Tierra, 2008). La población de estudio estuvo constituida por 6500 turistas nacionales y 9200 turistas extranjeros que arribaron a la ruta del tren del Hielo Tramo II Ambato-Cevallos-Urbina y al cantón Baños de Agua Santa. C, en el año 2014. La muestra estuvo constituida por 117 turistas nacionales y 118 turistas extranjeros que visitan la provincia de Tungurahua, la cual fue diseñada para tal efecto en virtud de variables sociográficas, psicográficas y motivacionales, posteriormente se tabuló, sistematizó y se interpretó los datos obtenidos, lo que permitió determinar el perfil del turista.

Para el análisis situacional del cantón Quero se aplicó, la matriz FODA, la que permitió identificar las fortalezas, oportunidades, debilidades y amenazas de la situación real en la que se encuentra el territorio, y la matriz CPES, que ayudó a la identificación de las causas que generan la problemática, así como también las posibles soluciones orientadas al desarrollo de la actividad turística.

Para el desarrollo del marco filosófico y estratégico del plan, se realizaron talleres con la participación de todos los actores e involucrados en la actividad turística a nivel cantonal, en estos se analizó la problemática existente dentro del sector turístico, en base a las matrices FODA y CPES, formulándose la; Misión, Visión, Principios y valores, Políticas y Objetivos estratégicos del plan. 
La estructura de los programas y proyectos para fortalecer el desarrollo del turismo, se tomaron en cuenta los resultados obtenidos en el diagnóstico y análisis situacional del cantón, especialmente de los resultados de la matriz CPES, los cuales se utilizó como línea base para la formulación de programas y proyectos, mismos que se planteó de acuerdo al formato SENPLADES, y en estrecha concordancia con el Plan Nacional del Buen Vivir (2009-2013), PLANDETUR 2020 y los Planes de Ordenamiento Territorial provincial y cantonal, de esta manera se pretende contribuir al desarrollo del turismo sostenible del cantón. Los programas han de tener la siguiente estructura: Nombre del programa, Justificación del programa, Objetivos del Programa, Metas del Programa, Beneficiarios, Actividades, Período de cumplimiento y Presupuesto del programa. Y en cuanto a la elaboración de los proyectos se utilizará la siguiente estructura: Nombre del proyecto, Beneficiario del proyecto, Duración del proyecto, Resumen narrativo del proyecto (fin, propósito, componentes y actividades), Indicadores verificables objetivamente, Medios de verificación, Supuestos y Presupuesto aproximado del proyecto. La elaboración e implementación del plan operativo anual (POA), se hizo en base a los proyectos y actividades elaborados, para lo cual se utilizó el Diagrama de Gantt proyectado para cinco años considerando los siguientes componentes: Nombre del proyecto, las actividades de cada proyecto, responsables, tiempo de ejecución y presupuesto.

\section{Análisis y discusión de los resultados}

Los diagnósticos situacionales del potencial turístico y de las características generales del Cantón Quero, se hicieron a través de la búsqueda de información en mapas topográficos, estudios económicos de las entidades locales regionales y nacionales de planificación y administración, información sobre estadísticas y censos, fotografías aéreas o terrestres, directorios locales y regionales; y oficinas de turismo gubernamentales locales y regionales, entre otras fuentes información.

\section{A. En relación con la evaluación del potencial turístico}

El cantón Quero está ubicado en la provincia de Tungurahua. Geográficamente está situada en la zona 17 Sur en las siguientes coordenadas (referencia el datum WGS 84): Su división política administrativa son Comunidades la matriz, parroquia La Matriz; Comunidades Rumipamba, parroquia Rumipamba y Comunidades Yanayacu parroquia Yanayacu. Limita por el norte con el

270 Vol. 5, núm. 1, enero, 2019, pp. 263-289

Catalina M. Verdugo Bernal, Julia D. Velástegui Cáceres, Cecilia T. Limaico Nieto, Diana P. Salazar Andrade, Ana C. Flores Mancheno 
Cantón Cevallos, al sur con el Cantón Guano provincia de Chimborazo, al este con el Cantón Pelileo y Oeste con el Cantón Mocha. Sus vías de acceso es la de Cevallos, Coca Cola - Llimpe San Vicente, Puente de Mocha y Guano - Sabañag - Santuario - El Placer.

Para el transporte, existen tres cooperativas que prestan el servicio intercantonal e interprovincial: La cooperativa Cevallos, Santiago de Quero realizan básicamente el servicio intercantonal entre la ciudad de Quero y la ciudad de Ambato. La cooperativa San Lucas que presta su servicio hacia la provincia de Chimborazo con una sola frecuencia diaria.

Según el sistema de clasificación de los ecosistemas del Ecuador continental propuesto por el Ministerio del Ambiente, 2012. El cantón Quero pertenece al Bosque siempre verde montano alto y montano alto superior de páramo el que se encuentra entre los 2800 hasta los 3600 m.s.n.m.

En cuanto al uso del suelo, Quero tiene una importante extensión de territorio dedicada a la agroproducción, existe suelos aptos para pastos, bosques, cultivos. Se puede continuar con los procesos agro-productivos, sin embargo, hay que implementar procesos técnicos de recuperación y conservación acordes a la susceptibilidad del terreno, pues el 78.8\% de suelo de territorio tiene diferentes tipos de susceptibilidad a la erosión.

El clima del cantón corresponde en un $76 \%$ ecuatorial de alta montaña, seguido por un $23 \%$ Ecuatorial mesotérmico semihúmedo, y una extensión de territorio de 1\% Ecuatorial mesotérmico seco. La temperatura del cantón fluctúa entre los rangos desde 4 y 13 grados centígrados, y las precipitaciones oscilan entre 500 y $1000 \mathrm{ml}$.

$\mathrm{Su}$ ecología conserva intactos grandes y frondosos bosques, montañas que invitan al turista a internarse en un mundo lleno de aventura y curiosidad para explorar este paisaje natural. Quero es un cantón que presenta muchos atractivos que deleitan la vista de quienes lo visitan, en varios lugares se pueden observar una cascada que nacen de las vertientes del páramo, su caudal se desliza por enormes rocas dando origen a varias caídas.

El paisaje también está formado por claros abiertos para las chacras, la ganadería y los centros poblados; en muchas de las comunidades se puede encontrar el encanto de las viviendas de diseño antiguo (casas de techo de paja con adobe) y la modalidad de asentamiento moderno (casas de ladrillo y cemento) con una pequeña plaza central, formando un paisaje único rodeado de montañas 
con una vegetación exuberante que contrasta con los rayos del sol. (GAD Municipal del Cantón Quero, 2015),

Las diversas variedades de productos que constituyen la flora y fauna de la región, son utilizadas en su mayoría, para el consumo humano del cantón.

En Quero no existe un sistema hidrográfico importante, el principal encauzamiento es el río Quero, límite natural con el cantón Mocha que fluye en dirección Sur Oeste - Nor Este; aguas arriba de Quero, éste toma el nombre de Río Mocha y aguas abajo toma el nombre de Río Pachanlica, el que desemboca en el Río Ambato, este a su vez en el río Patate, el cual confluye con el Río Chambo formando el Río Pastaza que desemboca en el Río Amazonas.

En la parroquia La Matriz lastimosamente existe una falta de conciencia por parte de la mayoría de la población que quema la basura de sus hogares, este fenómeno provoca contaminación, pero podría ser solucionado si la gente conociera como manejar los desechos sólidos sobre todo con el reciclaje y elaboración de compost y abonos.

El 96.83\% de los pobladores del cantón Quero se auto identifican como grupo étnico mestizo, el $1.32 \%$ como indígenas, el $0.96 \%$ como blancos, el $0.52 \%$ como afroecuatorianos, el $0.22 \%$ como montubios, el $0.14 \%$ como otra etnia.

La población del Cantón Quero según el último censo poblacional y de vivienda 2010 es de 19.205 habitantes distribuidos de la siguiente manera:

Cuadro 1. Población

\begin{tabular}{|l|l|l|l|l|}
\hline \multirow{5}{*}{} & & URBANO & RURAL & TOTAL \\
\cline { 2 - 5 } & LA MATRIZ & 2.679 & 11.575 & 14.254 \\
\cline { 2 - 5 } & RUMIPAMBA & - & 2.973 & 2.973 \\
\cline { 2 - 5 } & YANAYACU - MOCHAPATA & - & 1.978 & 1.978 \\
\cline { 2 - 5 } & Total & $\mathbf{2 . 6 7 9}$ & $\mathbf{1 6 . 5 2 6}$ & $\mathbf{1 9 . 2 0 5}$ \\
\hline
\end{tabular}

Fuente: INEC Censo de Población y Vivienda, 2010

El abastecimiento de agua proviene en un $64.59 \%$ de red pública, el $28.60 \%$ se consume directamente del río, el $6.23 \%$ se origina de agua lluvia o albarrada y el $0.47 \%$ de pozos.

Solamente el área urbana del cantón que es Quero centro y algunas comunidades aledañas como: Llimpe grande, Llimpe chico, Zona libre, San Vicente, Pueblo Viejo, Shaushi, Puñachisag, 
Santuario, Hualcanga Santa Anita, Hualcanga San Luis, la parroquia Yanayacu en un 20\%, Mochapata, y la parroquia Rumipamba los barrios Luis López y la Primavera, cuentan con red pública de alcantarillado, mientras que en algunas comunidades eliminan las aguas servidas a través de pozos ciegos, pozos sépticos, descargas directas al río o a campo abierto.

El 48.02\% de viviendas del cantón drenan sus aguas residuales a través de una red pública o alcantarillado, el $22.9 \%$ posee pozo séptico, el 17\% pozo ciego, el $8.67 \%$ no tienen ningún tipo de alcantarillado, el $2.31 \%$ realizan descarga directa al río y el $1.09 \%$ posee letrinas.

El servicio de energía es el que logra brindar mayor cobertura; la energía es proporcionada desde la red de la empresa eléctrica del cantón Quero en un 93.79\%; el 5.78\% no cuenta con este servicio (sin embargo, cuando se daña un transformador o algún componente facilitador del servicio en el área rural, su recuperación puede durar hasta 2 días debido a la difícultad del acceso a ciertos lugares del cantón); el $0.41 \%$ usa otro tipo de energía y el $0.02 \%$ restante obtiene energía a través de generador de luz.

La empresa encargada de proveer el servicio de telefonía convencional en el cantón Quero es la Corporación Nacional Telefónica (CNT), sin embargo, las líneas son escasas puesto que para tener acceso a una nueva línea hay que viajar hasta la ciudad de Ambato para realizar la petición respectiva, lo que representa un obstáculo para poder acceder a este servicio. Únicamente el $14.50 \%$ de la población posee le servicio de telefonía convencional, mientas que el $85.50 \%$ no.

A nivel nacional los asentamientos humanos han adoptado patrones culturales occidentales, el Cantón Quero no ha sido la excepción de estos cambios culturales, especialmente los adolescentes tienen esa inclinación de escoger costumbres y tradiciones que no sean propias de sucultura.

Cada año y durante fechas específicas se dan acontecimientos que por décadas se han venido realizando varias tradiciones en el Cantón, que son considerados como parte de la cultura de este sector. Estas fechas son muy importantes ya que en estos eventos las personas se reúnen con algún motivo especial para olvidarse un momento de las múltiples actividades y preocupaciones diarias y disfrutar de los diversos eventos. 
En el Cantón Quero existen algunos platos típicos como las papas con cuy, mote, queso y habas acompañadas de la tradicional chicha de jora o aguas aromáticas. Dicho alimento lo consumen con mayor frecuencia en tiempo de fiestas.

En el Ámbito Político administrativo, su estructura política y administrativa posee el Gobierno Local que tiene un orgánico estructural conformado por los siguientes niveles administrativos: Nivel Superior Legislativo conformado por el Consejo Municipal, Nivel Ejecutivo representado por la Alcalde, Nivel Asesor integrado por las comisiones y sindicatura, Nivel Auxiliar, secretaría y archivo del Consejo, Nivel Operativo conformado por los departamentos: Administrativo, Financiero, Justicia, policía y Vigilancia, Educación y Cultura, Higiene Ambiental, Obras Públicas, Proyectos y Desarrollo Social, Patronato, Unidad de Riesgo, Planificación y Jefatura de Obras Públicas.

La comercialización de leche fría y yogurt a través de la asociación APROLEQ, el queso fresco y queso andino a través de la asociación Hualcanga San Luis. Se impulsa procesos de comercialización a través de ferias agropecuarias y de leguminosas en la comunidad de Shaushi. Las cadenas más importantes en el cantón son: la papa, lácteos, cuyes, y hortalizas.

En el aspecto agropecuario se comercializa ganado en pie y derivados como queso y leche principalmente en Ambato. Tradicionalmente la venta de ganado se realiza en las comunidades de cada propietario, actualmente se lo hace en "la feria de ganado en pie" que se lleva a cabo en el Mercadeo de animales mayores ubicado en Marcopamba de Quero y porcinos, aves, cuyes, en el Barrio el Recreo los domingos.

El comercio del ganado para el camal se realiza a través de pequeños comerciantes, tercenistas o introductores, mismos que se encargan de recorrer las comunidades y de comprar el ganado que estará disponible para la venta en el camal del cantón y de los cantones cercanos como Pelileo, Cevallos, Mocha.

Las transacciones o negociaciones se realizan mediante estimaciones del peso vivo "al ojo", es decir a criterio de los compradores que en muchos casos no están acorde al peso real del ganado. El pago se suele hacer en partes, primero un anticipo de dinero al propietario para asegurar los lotes de ganado. Los pequeños comerciantes llevan el ganado al centro del mercado para ofrecerlo 
a los tercenistas o introductores, estos compran el ganado y lo transportan a los camales cercanos al Cantón donde serán faenados y comercializados por cuenta propia.

En la comunidad El Rosario crean los más bellos y prácticos artículos de madera que adornaron las cocinas, salas y dormitorios de cientos de hogares que apreciaron su habilidad, sus artesanías más vendidas son cucharas, bateas, rodillos etc. Son pintadas, talladas y decoradas con colores atractivos que no solo sean utilizables, sino luzcan bien en el espacio que se los vaya a poner. En lo referente a artesanías en el cantón sobresalen la carpintería, mueblería y la fabricación de carrocerías de madera. En la comunidad de San Vicente existen también microempresas relacionadas principalmente con la construcción de muebles, puertas y ventanas.

Inventario de atractivos turísticos, dentro de ellas se encuentran el Cerro Igualata, Durante el recorrido al Cerro Igualata se puede apreciar una gran variedad de especies de:

Flora: Almohadilla (Azorella aretioides), chilca (Prunus cefolia), orejuelo (Lachemilla orbiculata Rydb.) llantén de páramo (Plantago australis), chuquiragua (Chuquiraga jussieui).

También cuenta con el Mirador Hierba Buena y la Iglesia de la Virgen del Monte; La cascada de "Jun Jun" recibe este nombre en honor a un cacique que habitaba esta zona. Es un sitio natural muy singular que se encuentra en medio de rocas basálticas y un bosque de eucaliptos, que dominan las colinas y la ribera del río Pachanlica.

Los cerros Llimpe son de los más imponentes con los que cuenta el cantón Quero, constituye un mirador natural y desde aquí se puede observar los Altares, el volcán Tungurahua, Cotopaxi, Chimborazo, Puñalica. Y los cantones Quero, Tisaleo, Mocha, Cevallos y algunos cerros del Chimborazo. La Quinta Ecológica "La Playa" es la primera en el cantón que posee agroturismo, participar en una recolecta de frutas como la mora, uvilla y fresas. Se puede visitar las cayeras, conejeras, deleitar con comida típica a partir de materias recogidas por el propio turista.

El cantón Quero cuenta con un parque central, pero éste tiene una singular característica, posee una pileta que guarda en su memoria casi un siglo de historia. Construida en la década de 1920 con piedras labradas traídas desde la ciudad de Ibarra en lomo de acémilas. Así como el Santuario Diocesano de Nuestra Señora del Monte. 
Las colchas taurinas artesanales tratan de una mujer de 75 años que elabora espectaculares diseños en sus telas. Aprendió a bordar artesanalmente las colchas taurinas que desde hace años son parte de las festividades de varios de los pueblos del cantón Quero.

El estudio de mercado, indicó que el 59\% de la demanda nacional pertenece al género femenino y el $41 \%$ al género masculino. La demanda nacional posee edades entre 29 y 38 años que corresponde al 44\%; el 31\% lo conforman personas con edades 18 y 28 años; el 13\% entre 40 y 50 años; el 9\% entre 51 y 61 años y solamente el 3\% supera los 62 años.

El 50\% de la demanda nacional cuenta con nivel de instrucción universitario; $36 \%$ cuenta con estudios secundarios; el 12\% tiene estudios primarios y el 3\% restante ha obtenido un posgrado. Su principal motivación para realizar sus viajes son las vacaciones, correspondientes al 51\%; el $26 \%$ por estudios; el $15 \%$ viaja por negocios; y el $8 \%$ por otras razones. Suelen viajar acompañadas mayoritariamente por familiares; correspondiente al 52\%; el 28\% viaja en pareja; el 15\% con amigos; el 3\% restante con otro tipo de personas y el 2\% solo. El $81 \%$ de la demanda nacional expresó que no conoce el cantón Quero, mientras que el 19\% restante si lo ha visitado anteriormente y el 88\% comentó que, si visitase el cantón Quero, mientras que el 12\% expresó que no le interesaría.

La demanda nacional optó como tipo de turismo preferido el de naturaleza, correspondiente al 44\%; el 30\% eligió el turismo cultural; el 15\% el agroturismo; el 9\% de aventura; y el 2\% otro tipo de turismo. Prefieren realizar todas las actividades que constan en este ítem, correspondiente al 61\%; el 10\% eligió la fotografía; 7\% camping; el 5\% caminatas; 4\% observación de flora y fauna y cabalgata; el 2\% restante prefiere la observación de aves. Opinan que necesita los servicios de alimentación, transporte, hospedaje, guías en un 56\%; el 25\% necesita el servicio de alimentación; el 10\% hospedaje; el 5\% guías y 3\% transporte. Por otro lado, comentaron que para realizar sus viajes se informan mediante internet, correspondiente al $61 \%$; el $21 \%$ por la tv y el $10 \%$ por la familia o amigos; el $6 \%$ por medio de la radio; y el $2 \%$ restante por agencias de viaje.

La demanda nacional prefiere realizar sus viajes a finales del año (septiembre-diciembre), correspondiente al 58\%; el 26\% a mediados del año (mayo-agosto) y el 15\% restante a inicios del año (enero-abril) y requiere de 1 a 3 días para sus viajes, correspondiente al 52\%; el 29\% necesita de 4 a 6 días y el 19\% más de 6 días. Gastan un promedio de entre 10 y 20 dólares diarios durante 
sus viajes de turismo, correspondiente al 57\%; el 25\% gasta entre 21 y 30 dólares; el $15 \%$ entre 31 y 40 dólares y el 3\% más de 40 dólares. La mayoría provienen de la ciudad de Quito (40\%) y de Latacunga (24\%), pertenece al género masculino (41\%) y al femenino (59\%), poseen edades entre 29 - 39 años (44\%), en lo referente al estado civil la mayoría están casados (41\%), cuentan con nivel de educación universitaria (50\%) y secundaria (36\%).

La principal motivación de viaje de la demanda nacional consiste en las vacaciones (45\%), suelen viajar mayoritariamente con familiares (52\%), y en grupos de 3 y 5 personas $(60 \%)$ y expresaron que no conoce el cantón Quero (81\%) pero que si estuviese interesados en visitar esta localidad (88\%). Optaron como tipo de turismo preferido el de naturaleza (44\%) y el cultural (30\%); le gustaría realizar actividades como caminatas, intercambio cultural, observación de flora y fauna de la zona, cabalgatas, fotografía, camping, y observación de aves (61\%).Para realizar sus viajes, se informa de sus destinos turísticos mediante internet (61\%), prefieren realizar sus viajes a finales del año, es decir entre los meses septiembre y diciembre (58\%) y a mediados del año, o sea entre los meses de mayo y agosto (26\%), requieren de 1 a 3 días para sus visitas (52\%) y gastan un promedio de entre 10 y 20 dólares diarios durante sus viajes de turismo (57\%).

La mayor parte de la demanda extranjera proviene de EEUU, correspondiente al 40\%; el 22\% proviene de Holanda; el 16\% de Colombia; el 8\% de Alemania; el 7\% Francia el 5\% de Argentina; el $2 \%$ restante proviene de Canadá, en la cual el $57 \%$ pertenece al género masculino y el $43 \%$ al género femenino. Poseen edades entre 29 y 39 años; que corresponde al 38\%; el 27\% lo conforman personas con edades entre 18 y 28 años; el 16\% entre 40 y 50 años; el 13\% entre 51 y 61 años y solamente el $6 \%$ supera los 62 años.

La principal motivación que posee la demanda extranjera para realizar sus viajes son las vacaciones, correspondientes al 79\%; el $13 \%$ viaja por negocios; el $7 \%$ por estudios y el $2 \%$ por otras razones.

Las personas de la demanda extranjera suelen viajar en pareja en un 45\%; y el 29\% viaja con amigos; solos correspondiente al 15\% el 10\% con la familia; y el 1\% restante con otro tipo de personas.

La demanda extranjera suele viajar mayormente acompañada entre 2 personas; correspondiente al $55 \%$; el $33 \%$ entre 3 - 5 personas; el 10\% entre 6 y 8 personas y el 2\% restante viaja con más de 8 
personas, en la que el 97\% expresó que no conoce el cantón Quero y comentaron que si visitase el cantón.

La demanda extranjera optó como tipo de turismo preferido el de naturaleza, correspondiente al 47\%; el $28 \%$ eligió el agroturismo; el 13\% el cultural; el 10\% el de aventura y el 2\% otro tipo de turismo. Prefieren realizar todas las actividades que constan en este ítem, correspondiente al 55\%; el 18\% eligió las caminatas; $15 \%$ cabalgatas; el 10\% fotografía; 5\% camping; 3\% observación de flora y fauna y el $2 \%$ restante prefiere la observación de aves.

La demanda extranjera opina que necesita los servicios de alimentación, transporte, hospedaje, Guianza en un 92\%; el 3\% necesita el servicio de alimentación y transporte; y por último necesitan solo Guianza $2 \%$ y hospedaje el 1\%., y se informan mediante internet, correspondiente al 73\%; el $11 \%$ por medio de la tv; el $8 \%$ por agencias de viajes; y por familia y amigos. Asimismo, prefieren realizar sus viajes a mediados del año (mayo-agosto) en un 57\% y a finales del año (septiembrediciembre), correspondiente al 31\%; y el $12 \%$ restante a inicios del año (enero-abril).

La demanda extranjera opina que requiere de 4 a 6 días para sus viajes, lo que corresponde al 53\%; el 29\% de 1 a 3 días, y más de 6 días el 18\%; están dispuestos a gastar diariamente de \$21 a \$30, representando el 55\%; el 28\% de \$31 a \$40, de \$10 a \$20 en un 11\%, y un 6\% más de $\$ 40$. Proviene en su mayoría de EEUU (40\%) y de Holanda (22\%), el 57\% pertenece al género masculino y $43 \%$ al femenino; poseen edades entre 29 y 39 años (38\%), y su principal motivación de viaje consiste en las vacaciones $(79 \%)$ y los negocios $(13 \%)$, suelen viajar mayoritariamente en pareja (45\%) y en amigos (29\%).[G1]

La demanda extranjera prefiere el turismo de naturaleza (47\%) y agroturismo (28\%); le gustaría realizar actividades como caminatas, camping, intercambio cultural, observación de flora y fauna de la zona, cabalgatas, fotografía, y observación de aves (55\%) y opinan que los servicios turísticos con los que el cantón Quero debe contar, son los siguientes: la alimentación, el hospedaje, los guías $\mathrm{y}$ transporte en un $(92 \%)$.

Para realizar sus viajes, la demanda extranjera se informa acerca de sus destinos turísticos mediante internet (73\%), prefiriendo realizar sus viajes a mediados del año, es decir entre los meses (mayo - agosto) (57\%) y a final del año, o sea entre los meses de septiembre y diciembre (31\%), requieren 
de 4 a 6 días para sus visitas $(53 \%)$ y gastan un promedio de entre 21 y 30 dólares diarios durante sus viajes de turismo $(55 \%)$.

La oferta turística de la parroquia Matus no ha tenido un buen desarrollo, pese a que posee potencial turístico por lo que para realizar el análisis de la oferta se tomó en cuenta el sistema turístico, en base a los siguientes componentes:

El cantón Quero cuenta con alrededor de 16 atractivos turísticos entre los que se destacan miradores, cascadas, cadenas montañosas, comidas y bebidas, tejidos entre otros.

\section{B. Marco filosófico y estratégico del plan}

Misión. Ser un facilitador de procesos para el intercambio de información y vinculación de pequeños empresarios turísticos, privados, comunitarios y asociativos, interesados en promover la actividad turística, como estrategia de desarrollo económico, promoviendo espacios de reflexión sobre turismo sostenible en el territorio, impulsando la cultura de conservación del patrimonio cultural y ambiental a través de la investigación, el intercambio de experiencias, y promoviendo proyectos de beneficio de la población.

Visión. Quero para el año 2021 se conocerá como un cantón líder en la prestación de servicios turísticos a nivel provincial, con una oferta variada de productos que promuevan proyectos de inversión, siendo la actividad turística una de las principales fuentes de la economía local, generando plazas de empleo para sus habitantes en igualdad de condiciones. Considerándose al cantón Quero por los turistas como la mejor opción para visitar.

\section{Principios y valores}

Cooperación. - La cooperación en el cantón Quero, consiste en el trabajo en común llevado a cabo por parte de un grupo de personas o entidades mayores hacia un objetivo compartido. El trabajo cooperativo no compite, sino que suma fuerzas hacia el objetivo.

Eficacia. - El GAD municipal debe trabajar con eficacia para alcanzar una acción deseada, para el cumplimiento de proyectos planificados. 
Eficiencia. - Todos los objetivos propuestos para el desarrollo de la actividad turística deben cumplirse con eficiencia optimizando los recursos y garantizando su excelencia.

Honestidad. - Es un factor importante que todos los actores involucrados en el desarrollo turístico sean personas honestas que trabajen y luchen para alcanzar con los objetivos y propósitos establecidos.

Imparcialidad. - El GAD municipal debe trabajar con un criterio de justicia que sostenga sus decisiones a tomarse atendiendo a criterios objetivos, sin influencias de sesgos, prejuicios o tratos diferenciados por razones inapropiadas.

Participación. - Es muy importante que todos los actores involucrados en el sector turístico del cantón participen activamente en las actividades programadas para el desarrollo del turismo.

Responsabilidad. - El GAD municipal y actores involucrados en el sector turístico deben trabajar con responsabilidad para garantizar el correcto cumplimiento de los procesos establecidos que llevan al desarrollo del turismo del cantón.

Responsabilidad ambiental. - Poseen todos los pobladores del cantón Quero, a desarrollar actividades en el mismo y a considerar la responsabilidad que tienen con respecto a los potenciales daños ambientales.

Respeto. - Todos los procesos a realizarse para el desarrollo del turismo en la zona debe estar bajo un sentido de respeto entre todos los actores involucrados.

\section{Políticas}

El Gobierno Autónomo Descentralizado del cantón Quero (2014), es la institución responsable de la ejecución de los proyectos establecidos en el plan de desarrollo turístico sostenible, mediante la coordinación con las demás instituciones que trabajan en el cantón.

Las actividades turísticas para desarrollarse en el cantón están basadas en los ejes de la sostenibilidad, que promuevan la conservación de la naturaleza, el fortalecimiento de la identidad cultural y el crecimiento económico de la localidad. Para desarrollar el turismo se procurará en todo momento trabajar conjuntamente con todos los sectores turísticos de manera organizada, coordinada y participativa. 
Creación y ejecución de planes de conservación y manejo sostenible del patrimonio cultural y natural del cantón y fortalecimiento, capacitación y profesionalización en el área turística como base fundamental para el logro de un desarrollo turístico con perspectiva y proyección a futuro.

Mejoramiento de los servicios turísticos existentes en el cantón, optimizando su calidad y logrando a su vez la satisfacción de los turistas que visitan el cantón Quero y fortalecimiento en el ámbito social para impulsar el turismo procurando la integración de grupos sociales que han sido apartados a través del tiempo.

Involucramiento del sector privado y todas las comunidades del cantón en actividades relacionadas con el desarrollo del turismo.

Práctica del respeto y uso racional de los recursos mediante su conservación, manejo adecuado y control de las actividades a realizarse en territorios con potencial turístico; con énfasis en el turismo que garantice el buen vivir de la población y la preservación del patrimonio para el disfrute de futuras generaciones.

\section{Objetivos estratégicos}

- Consolidar al cantón Quero como un destino turístico en el que las actividades turísticas a desarrollarse tengan base en la sostenibilidad, que promuevan la conservación de la naturaleza, el fortalecimiento de la identidad cultural y el crecimiento económico de la localidad.

- Incentivar la protección y conservación del patrimonio natural y cultural del cantón.

- Proporcionar a los visitantes servicios de calidad mezclados con actividades turísticas que propicien un intercambio cultural y el disfrute de la naturaleza.

- Generar beneficios económicos a favor de la población minimizando y controlando los impactos negativos que el turismo no responsable pudiera ocasionar.

- Formar capacidades locales que trabajen en pro de la familia y de toda la localidad.

- Respetar y acatar ordenadamente las disposiciones establecidas en el marco legal turístico vigente. 
- Procurar la implementación de servicios básicos en buenas condiciones para mejorar la forma de vida de los pobladores del cantón.

- Garantizar al turista durante su tiempo de estadía: seguridad, orientación e información veraz y oportuna.

- Capacitar técnicamente en todos los aspectos relacionados con el turismo a los prestadores de servicios turísticos del cantón.

- Diseñar y ejecutar planes para promocionar turísticamente al cantón Quero, procurando tomar en cuenta los medios más eficientes de comunicación y estrategias idóneas que permitan dar a conocer la oferta turística del cantón.

- Satisfacer los requerimientos y necesidades del visitante actual mediante la diversificación de la oferta turística del cantón.

- Implementar sistemas de control de calidad de los servicios turísticos que se prestarán a las personas que visiten el cantón.

\section{Programas y proyectos de desarrollo turístico}

Quero es un cantón que posee un sin número de recursos para convertirse en un destino turístico importante dentro del territorio nacional, lamentablemente esta localidad no se ha desarrollado turísticamente debido a la falta de un plan estratégico diseñado con todos los requerimientos y procesos técnicos necesarios.

Luego de un minucioso análisis de la situación actual de esta población y tomando como base fundamental los parámetros establecidos en el PLANDETUR 2020, Plan de Marketing Turístico del Ecuador, Plan Nacional del Buen Vivir y en concordancia con las políticas y competencias establecidas del COOTAD, se proponen una serie de programas y proyectos que ayudarán a promover el turismo en esta zona, los cuales se presentan en cuadro 2. 
Dom. Cien., ISSN: 2477-8818

Vol. 5, núm. 1, enero, 2019, pp. 263-289

Propuesta de un plan de desarrollo turístico para la región geográfica del cantón Quero

Cuadro 2. Resumen de programas, proyectos y presupuesto del plan de desarrollo

\begin{tabular}{|c|c|c|c|c|c|}
\hline \multirow[b]{2}{*}{ PROGRAMA } & \multirow[b]{2}{*}{$\mathbf{N}^{\mathbf{o}}$} & \multirow[b]{2}{*}{ PROYECTO } & \multicolumn{3}{|c|}{ FINANCIAMIENTO } \\
\hline & & & INSTITUCIÓN & $\begin{array}{l}\text { PRESUPUESTO } \\
\text { DEL } \\
\text { PROYECTO }\end{array}$ & $\begin{array}{l}\text { PRESUPUESTO } \\
\text { DEL } \\
\text { PROGRAMA }\end{array}$ \\
\hline \multirow{2}{*}{$\begin{array}{l}\text { 1. Legislación } \\
\text { turística }\end{array}$} & 1.1 & $\begin{array}{l}\text { Socialización de la normativa } \\
\text { turística vigente del Ecuador }\end{array}$ & \multirow{2}{*}{$\begin{array}{l}\text { GADP TUNGURAHUA } \\
\text { GADM QUERO } \\
\text { MINTUR }\end{array}$} & 5000,00 & \multirow[b]{2}{*}{$8.900,00$} \\
\hline & 1.2 & $\begin{array}{l}\text { Generación de ordenanzas para } \\
\text { regular la actividad turística y } \\
\text { proteger el patrimonio natural y } \\
\text { cultural del cantón }\end{array}$ & & 3900,00 & \\
\hline \multirow{2}{*}{$\begin{array}{l}\text { 2. Señalética y } \\
\text { facilidades } \\
\text { turísticas }\end{array}$} & 2.1 & $\begin{array}{l}\text { Implementación } \quad y / o \\
\text { mejoramiento de señalética turística }\end{array}$ & \multirow{2}{*}{$\begin{array}{c}\text { GADP TUNGURAHUA } \\
\text { GADM QUERO } \\
\text { MINTUR } \\
\text { BNF }\end{array}$} & 31150,00 & \multirow[b]{2}{*}{$131.000,20$} \\
\hline & 2.2 & $\begin{array}{l}\text { Diseño e implementación de un } \\
\text { sistema de facilidades turísticas } \\
\text { orientadas a fortalecer los atractivos } \\
\text { del cantón }\end{array}$ & & 99850,20 & \\
\hline \multirow{2}{*}{$\begin{array}{l}\text { 3. Planta } \\
\text { turística }\end{array}$} & 3.1 & $\begin{array}{l}\text { Plan de capacitación para } \\
\text { prestadores de servicios turísticos. }\end{array}$ & \multirow{2}{*}{$\begin{array}{l}\text { GADP TUNGURAHUA } \\
\text { GADM QUERO } \\
\text { MINTUR }\end{array}$} & 5619,00 & \multirow[b]{2}{*}{$19.369,00$} \\
\hline & 3.2 & $\begin{array}{l}\text { Sistema de control de calidad para } \\
\text { los servicios turísticos ofertados en } \\
\text { el cantón. }\end{array}$ & & 13750,00 & \\
\hline \multirow{3}{*}{$\begin{array}{l}\text { 4. Ambiente y } \\
\text { cultura }\end{array}$} & 4.1 & Educación ambiental. & \multirow{3}{*}{$\begin{array}{c}\text { GADP TUNGURAHUA } \\
\text { GADM QUERO } \\
\text { MINTUR } \\
\text { MAE } \\
\text { INPC }\end{array}$} & 4450,00 & \multirow{3}{*}{$30.150,00$} \\
\hline & 4.2 & $\begin{array}{l}\text { Reforestación de las áreas naturales } \\
\text { que han sido afectadas por la } \\
\text { expansión de la frontera agrícola. }\end{array}$ & & 8600,00 & \\
\hline & 4.3 & Revitalización cultural. & & 17100,00 & \\
\hline \multirow{2}{*}{$\begin{array}{l}\text { 5. Promoción } \\
\text { turística }\end{array}$} & 5.1 & $\begin{array}{l}\text { Creación y difusión de un producto } \\
\text { turístico cantonal. }\end{array}$ & \multirow{2}{*}{$\begin{array}{l}\text { GADP TUNGURAHUA } \\
\text { GADM QUERO } \\
\text { MINTUR }\end{array}$} & 11800,00 & \multirow[b]{2}{*}{$42.100,00$} \\
\hline & 5.2 & $\begin{array}{l}\text { Plan de marketing turístico para el } \\
\text { cantón Quero. }\end{array}$ & & 30300,00 & \\
\hline
\end{tabular}


Dom. Cien., ISSN: 2477-8818

Vol. 5, núm. 1, enero, 2019, pp. 263-289

Propuesta de un plan de desarrollo turístico para la región geográfica del cantón Quero

\section{D. - Plan operativo anual (POA)}

TOTAL

Cuadro 3. POA del plan de desarrollo turístico del cantón Quero

\begin{tabular}{|c|c|c|c|c|c|c|c|c|c|c|c|c|c|c|c|c|c|c|c|c|c|c|}
\hline \multirow{3}{*}{ PROYECTO } & \multirow{3}{*}{ ACTIVIDADES } & \multirow{3}{*}{ RESPONSABLE } & \multicolumn{19}{|c|}{ CRONOGRAMA DE EJECUCION } & \\
\hline & & & \multicolumn{4}{|c|}{$\begin{array}{l}\text { AÑo } 1 \\
2017\end{array}$} & \multicolumn{4}{|c|}{$\begin{array}{l}\text { AÑO } 2 \\
2018\end{array}$} & \multicolumn{4}{|c|}{$\begin{array}{l}\text { AÑo } 3 \\
2019\end{array}$} & \multicolumn{4}{|c|}{$\begin{array}{l}\text { AÑo } 4 \\
2020\end{array}$} & \multicolumn{4}{|c|}{$\begin{array}{l}\text { AÑo } 5 \\
2021\end{array}$} \\
\hline & & & 1 & 2 & 3 & 4 & 1 & 2 & 3 & 4 & 1 & 2 & 3 & 4 & 1 & 2 & 3 & 4 & 1 & 2 & 3 & 4 \\
\hline \multirow{6}{*}{$\begin{array}{l}\text { Socialización de la } \\
\text { normativa turística } \\
\text { vigente del } \\
\text { Ecuador. }\end{array}$} & $\begin{array}{l}\text { C1.A1. Compilación de la } \\
\text { información acerca de la normativa } \\
\text { que rige al turismo en el Ecuador. }\end{array}$ & \multirow{6}{*}{$\begin{array}{c}\text { Gobierno } \\
\text { autónomo } \\
\text { descentralizado } \\
\text { del cantón Quero }\end{array}$} & & & & & & & & & & & & & & & & & & & & \\
\hline & $\begin{array}{l}\text { C1.A2. Establecer nexos con el } \\
\text { Ministerio de Turismo para } \\
\text { fomentar un programa de } \\
\text { capacitación. }\end{array}$ & & & & & & & & & & & & & & & & & & & & & \\
\hline & $\begin{array}{l}\text { C1.A3. Establecer los lineamientos } \\
\text { y metodología de la capacitación. }\end{array}$ & & & & & & & & & & & & & & & & & & & & & \\
\hline & $\begin{array}{l}\text { C2.A1. Elaboración de folletos } \\
\text { didácticos con la información a ser } \\
\text { socializada. }\end{array}$ & & & & & & & & & & & & & & & & & & & & & \\
\hline & $\begin{array}{l}\text { C2.A2. Convocatoria a los actores } \\
\text { turísticos y selección de los } \\
\text { participantes. }\end{array}$ & & & & & & & & & & & & & & & & & & & & & \\
\hline & $\begin{array}{l}\text { C2.A3. Ejecutar talleres } \\
\text { participativos para socialización de } \\
\text { la normativa turística }\end{array}$ & & & & & & & & & & & & & & & & & & & & & \\
\hline \multirow{7}{*}{$\begin{array}{l}\text { Generación de } \\
\text { ordenanzas para } \\
\text { regular la actividad } \\
\text { turística y proteger } \\
\text { el patrimonio } \\
\text { natural y cultural } \\
\text { del cantón. }\end{array}$} & $\begin{array}{l}\text { C1.A1. Identificar a todos los } \\
\text { involucrados en el sector turístico }\end{array}$ & \multirow{7}{*}{$\begin{array}{c}\text { Gobierno } \\
\text { autónomo } \\
\text { descentralizado } \\
\text { del cantón Quero }\end{array}$} & & & & & & & & & & & & & & & & & & & & \\
\hline & $\begin{array}{l}\text { C1.A2. Realizar un análisis } \\
\text { detallado de intereses de los actores, } \\
\text { en relación a aspectos turísticos }\end{array}$ & & & & & & & & & & & & & & & & & & & & & \\
\hline & $\begin{array}{l}\text { C1.A3. Ejecutar talleres } \\
\text { participativos con los actores } \\
\text { turísticos para definir la propuesta. }\end{array}$ & & & & & & & & & & & & & & & & & & & & & \\
\hline & $\begin{array}{l}\text { C1.A4. Formular la propuesta de } \\
\text { ordenanza }\end{array}$ & & & & & & & & & & & & & & & & & & & & & \\
\hline & $\begin{array}{l}\text { C2.A1. Socializar y validar las } \\
\text { ordenanzas propuestas }\end{array}$ & & & & & & & & & & & & & & & & & & & & & \\
\hline & $\begin{array}{l}\text { C2.A2. Expedir la ordenanza en el } \\
\text { registro oficial }\end{array}$ & & & & & & & & & & & & & & & & & & & & & \\
\hline & C2.A3. Implementar la ordenanza & & & & & & & & & & & & & & & & & & & & & \\
\hline
\end{tabular}


Dom. Cien., ISSN: 2477-8818

Vol. 5, núm. 1, enero, 2019, pp. 263-289

Propuesta de un plan de desarrollo turístico para la región geográfica del cantón Quero

\begin{tabular}{|c|c|c|c|c|c|c|c|c|c|c|c|c|c|c|c|c|c|c|c|c|c|}
\hline & & & \multicolumn{4}{|c|}{$\begin{array}{c}\text { AÑO 1 } \\
2017 \\
\end{array}$} & \multicolumn{4}{|c|}{$\begin{array}{l}\text { AÑO } 2 \\
2018\end{array}$} & \multicolumn{3}{|c|}{$\begin{array}{l}\text { AÑO 3 } \\
2019 \\
\end{array}$} & \multicolumn{4}{|c|}{$\begin{array}{c}\text { AÑO } 4 \\
2020 \\
\end{array}$} & \multicolumn{4}{|c|}{$\begin{array}{c}\text { AÑO } 5 \\
2021 \\
\end{array}$} \\
\hline & & & 1 & 2 & 3 & 4 & 1 & 2 & 3 & & 12 & 3 & 4 & 1 & 2 & 3 & 4 & 1 & 2 & & 4 \\
\hline & $\begin{array}{l}\text { C1.A1. Contratar la consultoría para } \\
\text { la elaboración del plan integral de }\end{array}$ & & & & & & & & & & & & & & & & & & & & \\
\hline \multirow{4}{*}{$\begin{array}{l}\text { Implementación } \\
\text { y/o mejoramiento } \\
\text { de señalética } \\
\text { turística }\end{array}$} & señalética turística, dicho plan. & \multirow{4}{*}{$\begin{array}{l}\text { Gobierno } \\
\text { autónomo } \\
\text { descentralizado } \\
\text { del cantón Quero } \\
\text { MINTUR }\end{array}$} & & & & & & & & & & & & & & & & & & & \\
\hline & $\begin{array}{l}\text { C1.A2. Determinar el presupuesto } \\
\text { necesario para la implementación } \\
\text { de la señalética }\end{array}$ & & & & & & & & & & & & & & & & & & & & \\
\hline & $\begin{array}{l}\text { C1.A3. Implementación del } \\
\text { proyecto }\end{array}$ & & & & & & & & & & & & & & & & & & & & \\
\hline & $\begin{array}{l}\text { C1.A4. Definir acciones para } \\
\text { cuidado y mantenimiento de la } \\
\text { señalética turística }\end{array}$ & & & & & & & & & & & & & & & & & & & & \\
\hline \multirow{12}{*}{$\begin{array}{c}\text { Diseño e } \\
\text { implementación de } \\
\text { un sistema de } \\
\text { facilidades } \\
\text { turísticas } \\
\text { orientadas a } \\
\text { fortalecer los } \\
\text { atractivos del } \\
\text { cantón }\end{array}$} & $\begin{array}{l}\text { C1.A1. Elaborar el diagnóstico de } \\
\text { las condiciones actuales del sistema } \\
\text { de senderización }\end{array}$ & \multirow{12}{*}{$\begin{array}{l}\text { Gobierno } \\
\text { autónomo } \\
\text { descentralizado } \\
\text { del cantón Quero } \\
\text { MINTUR }\end{array}$} & & & & & & & & & & & & & & & & & & & \\
\hline & $\begin{array}{l}\text { C1.A2. Diseño arquitectónico del } \\
\text { sistema de senderización }\end{array}$ & & & & & & & & & & & & & & & & & & & & \\
\hline & $\begin{array}{l}\text { C1.A3. Dar mantenimiento a la } \\
\text { madera de las casetas de descaso } \\
\text { con un tratamiento de } \\
\text { impermeabilización }\end{array}$ & & & & & & & & & & & & & & & & & & & & \\
\hline & $\begin{array}{l}\text { C1.A4. Elaborar la propuesta } \\
\text { técnica del sistema de señalización } \\
\text { del cantón Quero }\end{array}$ & & & & & & & & & & & & & & & & & & & & \\
\hline & $\begin{array}{l}\text { C1.A5 Diseño del sistema de } \\
\text { señalética que cumpla con la } \\
\text { normativa turística } \\
\text { nacional vigente }\end{array}$ & & & & & & & & & & & & & & & & & & & & \\
\hline & $\begin{array}{l}\text { C1.A6. Implementación del sistema } \\
\text { de señalética }\end{array}$ & & & & & & & & & & & & & & & & & & & & \\
\hline & $\begin{array}{l}\text { C2.A1. Dar tratamiento a la madera } \\
\text { de impermeabilización y alisado } \\
\text { puesto que posee aristas cortantes, } \\
\text { tanto en el piso, pasamanos, } \\
\text { escalinatas. }\end{array}$ & & & & & & & & & & & & & & & & & & & & \\
\hline & $\begin{array}{l}\text { C2.A2. Dotar al sendero de } \\
\text { basureros ecológicos }\end{array}$ & & & & & & & & & & & & & & & & & & & & \\
\hline & $\begin{array}{l}\text { C2.A3.Dar mantenimiento a la } \\
\text { madera de las casetas de descaso } \\
\text { con un tratamiento de } \\
\text { impermeabilización }\end{array}$ & & & & & & & & & & & & & & & & & & & & \\
\hline & $\begin{array}{l}\text { C2.A4. Diseño e implementación de } \\
\text { señalética para el sendero }\end{array}$ & & & & & & & & & & & & & & & & & & & & \\
\hline & $\begin{array}{l}\text { C3.A1. Limpieza del centro de } \\
\text { información turística. }\end{array}$ & & & & & & & & & & & & & & & & & & & & \\
\hline & $\begin{array}{l}\text { C3.A2. Gestión para la obtención de } \\
\text { material publicitario y de } \\
\text { promoción turística del cantón. }\end{array}$ & & & & & & & & & & & & & & & & & & & & \\
\hline
\end{tabular}

\begin{tabular}{|c|c|c|c|c|c|c|c|c|c|c|c|c|c|c|c|c|c|c|c|c|}
\hline \multirow{3}{*}{ PROYECTO } & \multirow{3}{*}{ ACTIVIDADES } & \multirow{3}{*}{ RESPONSABLE } & \multicolumn{18}{|c|}{ CRONOGRAMA DE EJECUCION } \\
\hline & & & \multicolumn{4}{|c|}{$\begin{array}{c}\text { AÑO 1 } \\
2017\end{array}$} & \multicolumn{3}{|c|}{$\begin{array}{c}\text { AÑO 2 } \\
2018\end{array}$} & \multicolumn{4}{|c|}{$\begin{array}{c}\text { AÑO 3 } \\
2019\end{array}$} & \multicolumn{4}{|c|}{$\begin{array}{c}\text { AN̂́O } 4 \\
2020\end{array}$} & \multicolumn{3}{|c|}{$\begin{array}{c}\text { AÑO 5 } \\
2021\end{array}$} \\
\hline & & & 1 & 2 & & 4 & \begin{tabular}{l|l|} 
& 2 \\
\end{tabular} & 3 & 4 & 1 & 2 & 3 & 4 & 1 & $2 \mid 3$ & 35 & & 12 & & 4 \\
\hline $\begin{array}{c}\text { Plan de } \\
\text { capacitación para } \\
\text { prestadores de }\end{array}$ & $\begin{array}{l}\text { C1.A1. Identificar las necesidades } \\
\text { de capacitación de los prestadores } \\
\text { de servicios y personas } \\
\text { involucradas en el sector turístico }\end{array}$ & $\begin{array}{c}\text { Gobierno } \\
\text { autónomo } \\
\text { descentralizado } \\
\text { del cantón Quero }\end{array}$ & & & & & & & & & & & & & & & & & & \\
\hline
\end{tabular}

285 Vol. 5, núm. 1, enero, 2019, pp. 263-289

Catalina M. Verdugo Bernal, Julia D. Velástegui Cáceres, Cecilia T. Limaico Nieto, Diana P. Salazar Andrade, Ana C. Flores Mancheno 
Dom. Cien., ISSN: 2477-8818

Vol. 5, núm. 1, enero, 2019, pp. 263-289

Propuesta de un plan de desarrollo turístico para la región geográfica del cantón Quero

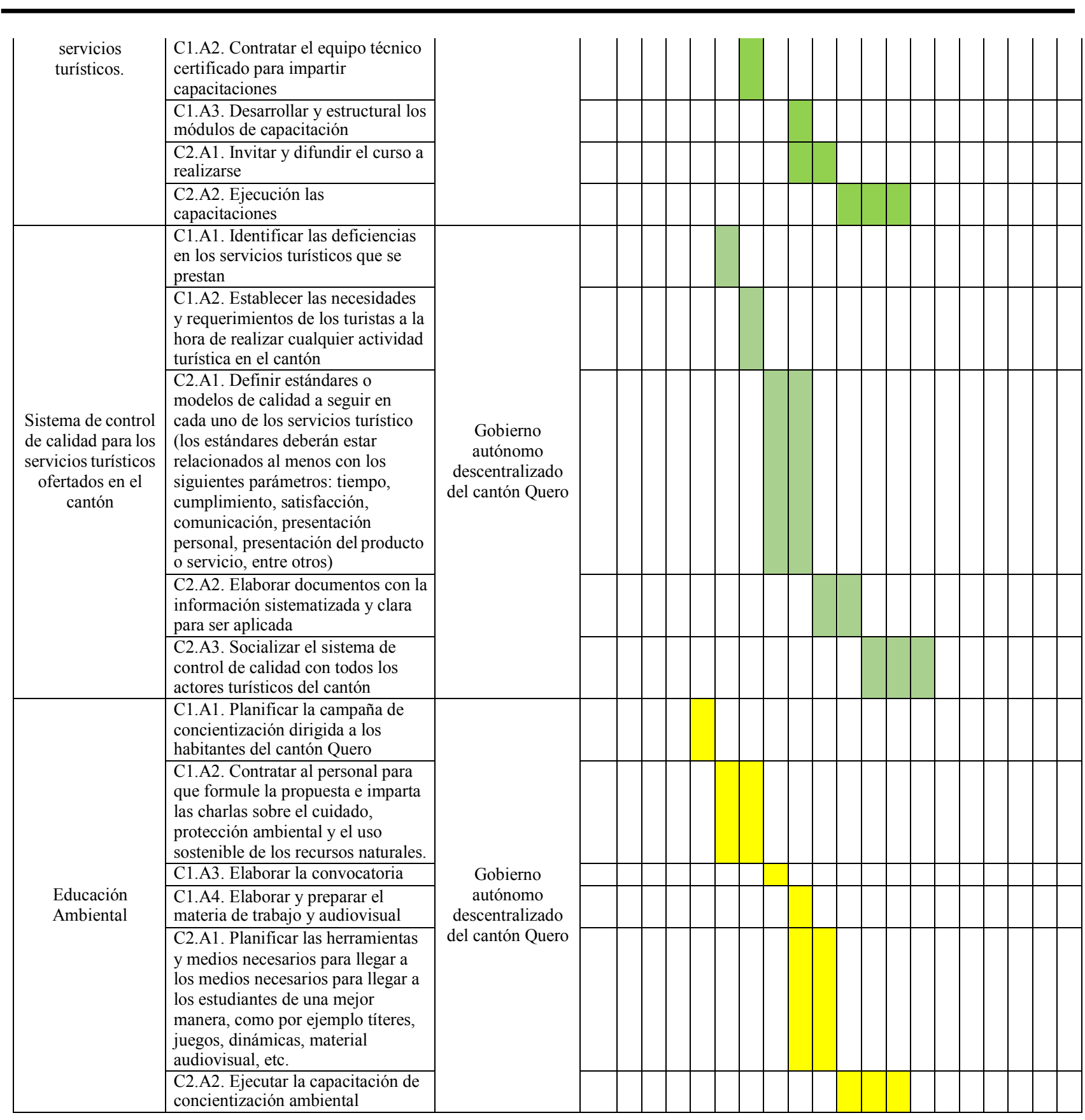

\begin{tabular}{|c|c|c|c|c|c|c|c|c|c|c|c|c|c|c|c|c|c|c|c|c|c|c|}
\hline \multirow{3}{*}{ PROYECTO } & \multirow{3}{*}{ ACTIVIDADES } & \multirow{3}{*}{ RESPONSABLE } & \multicolumn{20}{|c|}{ CRONOGRAMA DE EJECUCION } \\
\hline & & & \multicolumn{4}{|c|}{$\begin{array}{c}\text { AÑO 1 } \\
2017\end{array}$} & \multicolumn{4}{|c|}{$\begin{array}{c}\text { AÑO 2 } \\
2018\end{array}$} & \multicolumn{4}{|c|}{$\begin{array}{c}\text { AÑO 3 } \\
2019\end{array}$} & \multicolumn{4}{|c|}{$\begin{array}{c}\text { AÑO 4 } \\
2020\end{array}$} & \multicolumn{4}{|c|}{$\begin{array}{c}\text { AÑO 5 } \\
2021\end{array}$} \\
\hline & & & 1 & 2 & 3 & 4 & 1 & 2 & 3 & 4 & 1 & 2 & 3 & 4 & 1 & 2 & 3 & 4 & $\mathbf{1}$ & 2 & 3 & 4 \\
\hline \multirow{2}{*}{$\begin{array}{l}\text { Reforestación de } \\
\text { las áreas naturales } \\
\text { que han sido } \\
\text { afectadas por la } \\
\text { expansión de la } \\
\text { frontera agrícola }\end{array}$} & $\begin{array}{l}\text { C1.A1. Contratar a un técnico para } \\
\text { que realice la investigación de las } \\
\text { áreas afectadas así como también } \\
\text { las especies nativas de la zona }\end{array}$ & \multirow{2}{*}{$\begin{array}{c}\text { Gobierno } \\
\text { autónomo } \\
\text { descentralizado } \\
\text { del cantón Quero }\end{array}$} & & & & & & & & & & & & & & & & & & & & \\
\hline & $\begin{array}{l}\text { C1.A2. Elaborar y socializar el } \\
\text { documento con los resultados de la } \\
\text { investigación }\end{array}$ & & & & & & & & & & & & & & & & & & & & & \\
\hline
\end{tabular}


Dom. Cien., ISSN: 2477-8818

Vol. 5, núm. 1, enero, 2019, pp. 263-289

Propuesta de un plan de desarrollo turístico para la región geográfica del cantón Quero

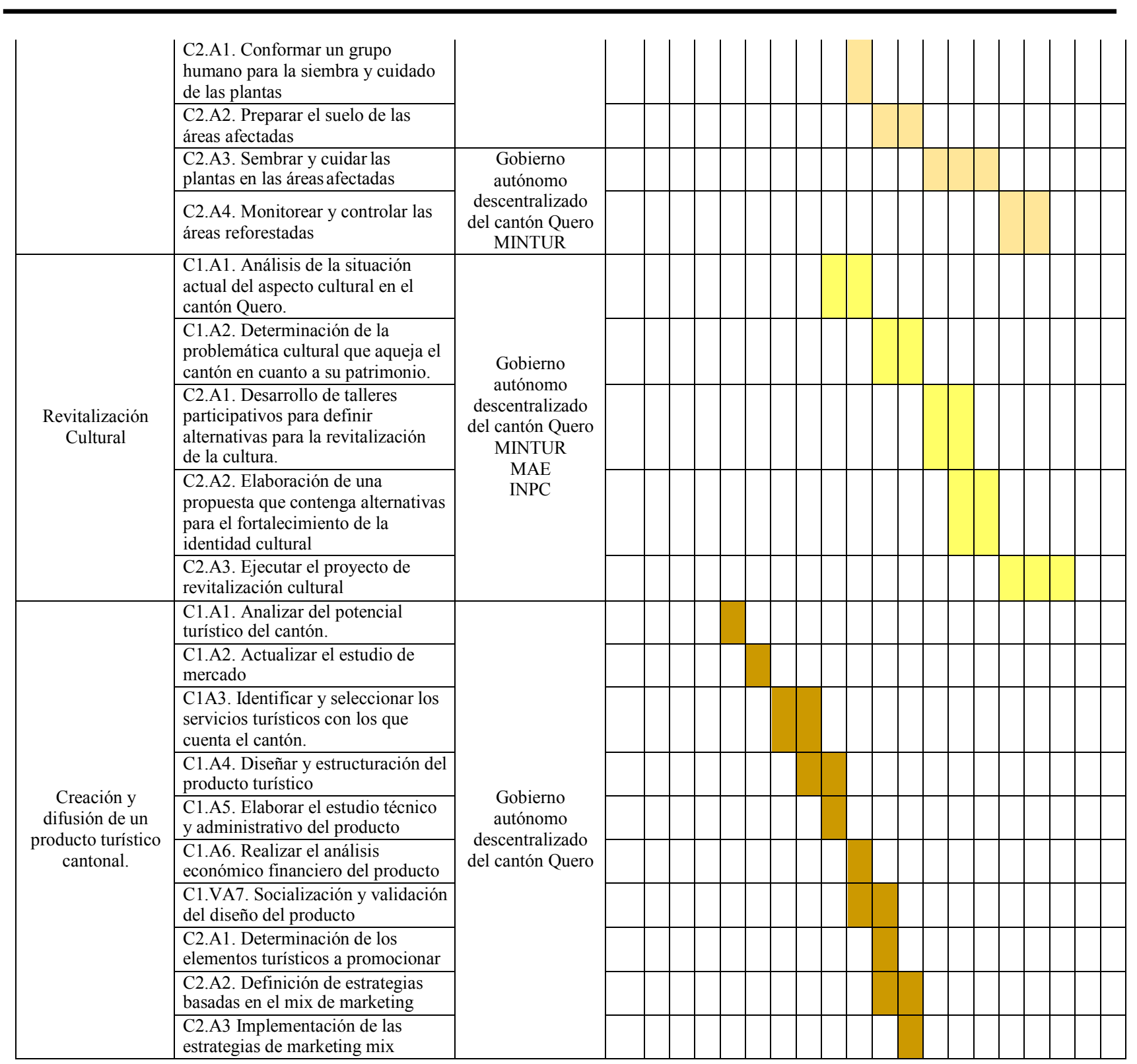

\begin{tabular}{|c|c|c|c|c|c|c|c|c|c|c|c|c|c|c|c|c|c|c|c|}
\hline \multirow{3}{*}{ PROYECTO } & \multirow{3}{*}{ ACTIVIDADES } & \multirow{3}{*}{ RESPONSABLE } & \multicolumn{17}{|c|}{ CRONOGRAMA DE EJECUCION } \\
\hline & & & \multicolumn{4}{|c|}{$\begin{array}{l}\text { AÑO 1 } \\
2017\end{array}$} & \multicolumn{3}{|c|}{$\begin{array}{c}\text { AÑO 2 } \\
2018\end{array}$} & \multicolumn{4}{|c|}{\begin{tabular}{c|} 
AÑO 3 \\
2019
\end{tabular}} & \multicolumn{3}{|c|}{$\underset{2020}{\text { AÑO } 4}$} & \multicolumn{3}{|c|}{$\begin{array}{c}\text { AÑO } 5 \\
2021\end{array}$} \\
\hline & & & 1 & 2 & 3 & 4 & 1 & 23 & 4 & 1 & $2:$ & \begin{tabular}{l|l}
3 & 4 \\
\end{tabular} & 1 & 122 & 3 & 4 & \begin{tabular}{l|l}
1 & 2 \\
\end{tabular} & \begin{tabular}{|l|l}
3 & 2 \\
\end{tabular} & 4 \\
\hline \multirow[t]{2}{*}{$\begin{array}{l}\text { Plan de marketing } \\
\text { turístico para el } \\
\text { cantón Quero. }\end{array}$} & $\begin{array}{l}\text { C1.A1. Actualizar el estudio de } \\
\text { mercado (autentificación de } \\
\text { segmentos de mercado, de acuerdo } \\
\text { a la tipología de productos con los } \\
\text { que cuenta el cantón) }\end{array}$ & \multirow[t]{2}{*}{$\begin{array}{c}\text { Gobierno } \\
\text { autónomo } \\
\text { descentralizado } \\
\text { del cantón Quero }\end{array}$} & & & & & & & & & & & & & & & & & \\
\hline & $\begin{array}{l}\text { C1.A2. Actualizar la marca turística } \\
\text { del cantón }\end{array}$ & & & & & & & & & & & & & & & & & & \\
\hline
\end{tabular}




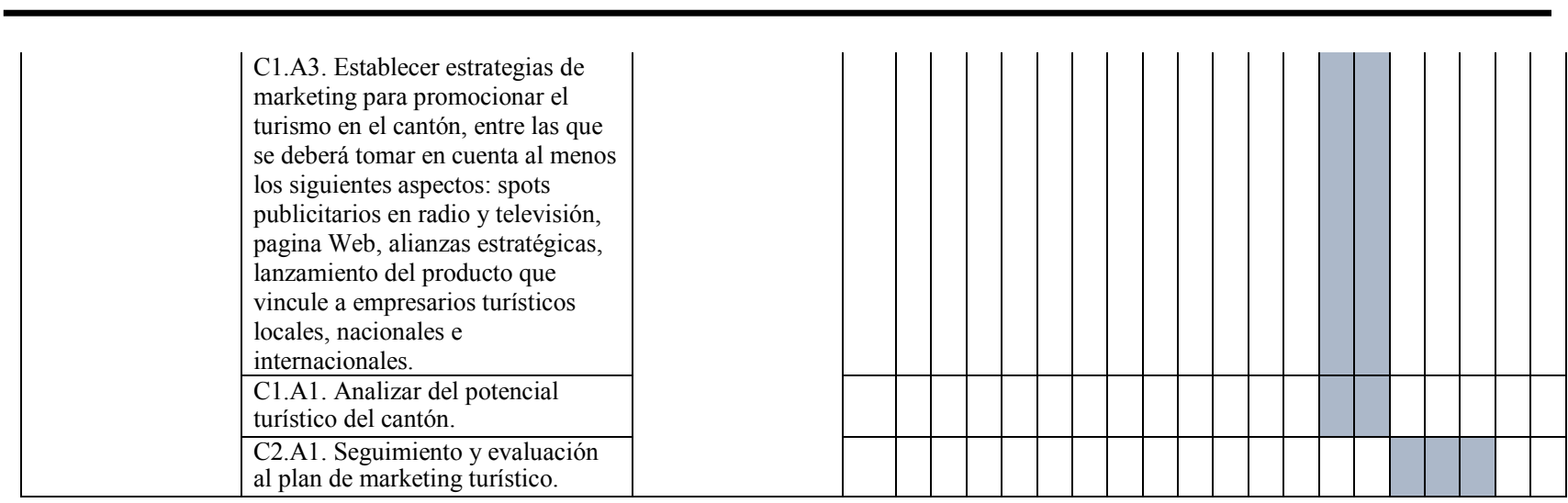

Fuente: Elaboración propia

\section{Conclusiones}

- El cantón Quero posee una gran riqueza natural y cultural, por lo que se constituyen en un importante componente para la diversificación de la oferta turística cantonal, su mayoría de atractivos pertenece a jerarquía II, se ven disminuida su puntuación por la falta de facilidades turísticas que impiden el acceso y disfrute de los atractivos.

- Existe un alto porcentaje de aceptación por parte de los turistas nacionales y extranjera para realizar turismo en el cantón, lo cual demuestra la existencia de un amplio mercado interesado en conocer y desarrollar actividades turísticas en el cantón Quero, por esta razón es importante que el mismo cuente con una oferta turística diversificada e innovadora, que fortalecida a través de alianzas estratégicas garantice el desarrollo sostenible del turismo parroquial.

- La planificación estratégica establecida para el Plan de Desarrollo Turístico del Cantón Quero, responde a lineamientos estratégicos mencionados en el PLANDETUR 2020 en concordancia con el Plan Nacional del Buen Vivir, es decir que están orientados estrictamente a mejorar o garantizar la calidad del destino y a su vez que contribuye al mejoramiento de la calidad de vida de la población local.

- La conveniente Gestión del plan de desarrollo turístico para el cantón Quero, ubica las bases para mejorar el desarrollo del turismo, incluyendo programas y proyectos que responden a las necesidades del sistema turístico, que eleven el nivel de competitividad de los productos turísticos a desarrollar a nivel cantonal, lo cual ayudará a generar beneficios económicos complementarios que se verán. 


\section{Referencias Bibliográficas}

Aguila, M. (2008). Como Elaborar un Proyecto. Hymanitas: Lumen.

Cajas y Tierra. (2008). Estudio de mercado. Recuperado el 12 de septiembre de 2015, de http://www.monografias.com/trabajos13/mercado.shtm

Gobierno Autónomo Descentralizado del cantón Quero. (2014). Características climáticas del cantón. Recuperado el 28 de septiembre de 2015, de http://www.quero.gob.ec

Horwath Argentina. (2006). Plan de desarrollo turístico. Recuperado el 12 de septiembre de 2015, de http://www.turismo.jujuy.gov.ar/descargas/plan/plan_de_desarrollo_turistico.pdf

Ministerio de Turismo de Ecuador. (2014). Inventario de atractivos turísticos. Recuperado el 5 de septiembre de 2015, de inventario de atractivos turísticos: http://es.scribd.com/doc/56382986/Metodologia-de-Inventario\#scribd

Organización Mundial de Turismo. (2007). Glosario básico de turismo. Recuperado el 23 de octubre de 2015, de http://media.unwto.org/es/content/entender-el-turismo-270

Plan Nacional del Buen Vivir. (2009). Objetivos nacionales para el buen vivir. Quito.

Saavedra, R. (2001). Planificación del Desarrollo, Colecciones Estudios de Economía. Recuperado el 22 de septiembre de 2015, de http://books.google.com.ec/books?id=rhq8XM

SECTUR (2012). Secretaría de Turismo. Recuperado en; www.sectur.gob.mx/pdf/InformesL/SECTUR_1ER_INFORME_LABORES_2013.pdf

Tierra, P. (2008). Evaluación del potencial turístico. Texto básico. En planificación territorial. Riobamba: ESPOCH.

World Travel (2014). Turismo a nivel mundial. Obtenido de http://www.wttc.org//media/files/reports/economic\%20impact\%20research/economic\%20impact\%202015\%20sum mary\%20spanish_web.pdf 